\title{
Presence of crystals in the synovial fluid of patients with psoriatic arthritis
}

\author{
Autors: \\ Stanislava Popova-Belova ${ }^{1}$, Mariela Geneva-Popova ${ }^{2}$, Velicka Popova ${ }^{3}$, Krasimir \\ $\mathrm{Kraev}^{4}$, Anastas Batalov ${ }^{5}$,
}

1. Department of Propedeutics of Internal Disease, Faculty of Medicine,

Medical University, Plovdiv, Bulgaria, "Vasil Apriliv" blvd 15-A,

Rheumatology, UMHAT “St. Georgi”, Plovdiv, Bulgaria

Phone: 0898523129

Email: Stanislava.Popova@mu-plovdiv.bg

2. Department of Propedeutics of Internal Disease, Faculty of Medicine,

Medical University, Plovdiv, Bulgaria, "Vasil Apriliv" blvd 15-A,

Rheumatology, UMHAT “St. Georgi”, Plovdiv, Bulgaria

Phone: 0898523128

Email: Mariela.Geneva@mu-plovdiv.bg, genevapopova@yahoo.com

3. Department of Propedeutics of Internal Disease, Faculty of Medicine,

Medical University, Plovdiv, Rheumatology, UMBAL "Kaspela" st. "Sofia" 64, email: Velichka.Popova@mu-plovdiv.bg,drvpopova@gmail.com

4. Department of Propedeutics of Internal Disease, Faculty of Medicine, Medical University, Plovdiv, Rheumatology, UMBAL "Kaspela"

st. "Sofia" 64, email: Krasimir.Kraev@mu-plovdiv.bg,kkraev@gmail.com

5. Department of Propedeutics of Internal Disease, Faculty of Medicine, 
Medical University, Plovdiv

Rheumatology, UMBAL "Kaspela"

st. "Sofia" 64, email: Anastas.Batalov@mu-plovdiv.bg, abatalov@ hotmail.com

These authors contributed equally to this work.

Correspondence: Assoc.Prof. Mariela Geneva-Popova, MD, PhD

Department of Propedeutics of Internal Disease, Faculty of Medicine,

Medical University, Plovdiv, Bulgaria, "Vasil Apriliv" blvd 15-A,

Rheumatology, UMHAT “St. Georgi”, Plovdiv, Bulgaria

Phone: + 359898523128

Email: Mariela.geneva@mu-Plovdiv.bg,genevapopova@yahoo.com

Summary: Analyzing synovial fluid from joints affected by the pathological process of psoriatic arthritis is part of the overall patient examination, since it may have differential diagnostic significance. The purpose of this study was to assess the presence of crystals in the synovial fluid of psoriatic arthritis patients as biomarkers for disease activity. Materials and methods: The synovial fluid of 156 patients with proven PSA diagnosis (patients covered CASPAR criteria) was analyzed over 24 months and compared to 50 patients with activated gonarthrosis. The Leica DM4500P polarization microscope (Leica Microsystems, Germany) was used for crystal detection. Pain and disease activity measures were also evaluated (PSA VAS for pain, DAPSA, PASDAI, mCPDAI and HAQ-DI). The statistical analysis was carried out using SPSS version 26 with significance set at $\mathrm{p}<0.05$.

Results: The macroscopic appearance of synovial fluid from patients with psoriatic arthritis was clear in $84.6 \%$ of the patients. Synovial fluid crystals were found in $23.71 \%$ of patients with psoriatic arthritis - predominantly monosodium urate $(67.58 \%)$ but also calcium pyrophosphate $(21.62 \%)$ and lipid drops $(5.4 \%)$. The presence of monosodium urate crystals significantly correlates with all pain and disease activity measures - VAS for pain, DAPSA, PASDAI, mCPDAI and HAQ-DI. In $67.56 \%$ of patients with established crystals treatment 
with an anti-TNF blocker was started at the discretion of the treating rheumatologist due to high levels of disease activity.

Conclusion: Examining the synovial fluid in PSA patients is a necessary minimally invasive procedure in cases of joint effusion, since the presence of synovial fluid crystals is a significant indicator of disease severity. The current analyses demonstrates that the presence of synovial fluid crystals in PSA patients can be used as a biomarker for disease severity and the necessity to commence biological treatment (most often TNF-a-blocker).

Keywords: synovial fluid, crystals, biomarker, PSA

\section{Introduction}

Psoriatic arthritis (PSA) belongs to a heterogeneous group of inflammatory joint diseases $(1,2,3)$. The relatively high incidence of the disease, the presence of extra-articular and systemic manifestations and the ongoing patient disability have significant socioeconomic implications (4).

Analyzing synovial fluid from joints affected by the pathological process of psoriatic arthritis is part of the overall patient examination, since it may have differential diagnostic significance. The synovial fluid of PSA patients has a multicomponent composition consisting of enzymes, metalloproteinase, proangiogenic factors, stretching factors, polypeptides and cells such as T-lymphocytes CD4+IL-17+ and CD8+IL17+, with a predominance of the latter, etc. $(5,6,7)$.

The diagnostic challenge of rheumatologists is to establish whether the synovial fluid of a PSA patient demonstrates any abnormalities. According to Shelley and Cornbleet, the analysis of synovial fluid and the identification of synovial fluid crystals is a challenge for any rheumatologist (8).

Daniel Mccarty and Joseph Hollander introduce polarized light microscopy as a way of examining synovial fluid to allow the identification of monosodium urate (MSU) and calcium pyrophosphate (CPPD) crystals (9). According to Krey and co-authors, the detection of synovial fluid crystals can change clinical diagnosis and management (10).

The preence of crystals in synovial fluid is due to one of the following reasons:

1. Crystallization of a substance with an increased plasma concentration

2. Formation of crystals as a result of a degenerative process involving calcification of cartilage and/or bone structure

3. Utilization of a substance after its introduction directly into the joint space (10)

MSU crystals are usually visualized in the form of medium-sized sticks or needles, while CPPD crystals are small and have the shape of a diamond, rhomboid or square (11). 
The identification of crystals in the synovial fluid is not always easy (12). Sources suggest that using polarized light microscopy to establish needle-shaped two-breaking crystals is the gold standard for diagnosing MSU. Werendsen and co-authors summarized specialists' presentation of crystalline identification in synovial fluid and report that the success rate was only $81 \%$ (13).

Swan and co-authors carried out a critical evaluation of the literature in an attempt to assess the present state of synovial fluid analysis in the diagnosis of joint diseases (14). The authors found that evidence of quality control in these studies was scarce and sensitivity, specificity and reliability tests demonstrated alarming variations (14). According to the same authors, difficulties in interpreting the results are a major obstacle to the clinical implementation of these analyses (14).

Ropes and Bauer were among the first to prove that differences in the appearance and cellular content of abnormal synovial fluid can be associated with different categories of diseases (15).

Using the keyword "synovial fluid," Shmerling identified 6,556 articles. Some of the publications analyzed biomarkers although most of them focused on analysing characteristics of synovial fluid without any potential clinical value. Only 200 articles directly related to the value of synovial fluid analysis in clinical diagnosis. Shmerling and co-authors critically evaluated the result of these analysis and concluded the following:

A. Critical assessment of traditional Gram staining and joint fluid culture testing there is limited data available to allow assessment of the sensitivity or specificity of these tests, as well as poor quality control of the available information and little evidence based on recommendations for their use. The sensitivity of culture testing is $75-95 \%$ and $50-75 \%$ for gram coloration, specificity is estimated at over $90 \%(15,16,17)$.

B. Critical assessment of counting molded elements - the total and differential number of white blood cells in synovial fluid provides a way of distinguishing between noninflammatory and inflammatory arthritis, neutrophil rates are a good guide to the degree of inflammation of the joints and therefore an indicator of severe acute conditions $(15,18)$

C. Critical assessment of the identification of MSU, CPPD crystals, etc. through polarized light microscopy - analysis of the sensitivity, specificity and reliability tests of crystals shows alarming problems and variations $(15,16,19,20)$.

Gordon and Swan demonstrate that the concentration of crystals in ssynovial fluid is important - the greater the load on the crystals in the synovial fluid, the more likely observers are to detec, evaluate and correctly diagnose them (14).

The study of synovial fluid through polarized light microscopy is an established diagnostic technique widely considered reliable for crystal detection. According to Gordon and Swan, the average sensitivity for MSU detection is 69\% and for CPPD - $82 \%$, and the average specificity for MSU detection is 97\%, and for CPPD - 78\% (14). 
Boumans and Hettema evaluated the added value of synovial fluid centrifugation for microscopic crystal detection in PSA patients (21). Two blinded observers used polarized light microscopy to assess smears for the presence of crystals before and after centrifugation. After centrifugation, no additional MSU crystal positive smears (21) were identified. The authors conclude that monosodium urate crystals are well recognized without centrifugation and that centrifugation has limited additional value to increase the amount of MSU-positive pap smears, as opposed to CPP (21).

Venkatasubramaniam and co-authors demonstrated for the first time in 1980 the simultaneous occurrence of psoriatic arthropathy and the 2 main types of crystal arthritis pseudogout and gout. Crystals found in aspirated synovial fluid and exudative leukocytes were identified by the authors using a polarizing microscope such as calcium pyrophosphate dihydrate in one case and sodium monourate in another (22). The authors concluded that both diseases occur simultaneously (22).

Oliviero and collaborators investigated the incidence of MSU and CPP in synovial fluid of patients with joint diseases (23). The authors found that CPP crystals were present in the synovial fluid of $22.28 \%$ of patients with OA, $8.28 \%$ of patients with RA, and only in $3.82 \%$ of patients with PSA. The prevalence of MSU crystals in RA patients was $0.30 \%$, $3.34 \%$, in patients with PSA, $0.70 \%$ in patients with a SPA in and in none of the patients with OA (23).

Galozzi P. and co-authors evaluated the presence and frequency of MSU crystals and calcium pyrophosphate (CPP) in synovial fluid aspirated from wrist and finger joints of patients with joint diseases (24). The predominance of MSU crystals in synovial fluid was $83.3 \%$ in gout, $10 \%$ in PSA, $2.8 \%$ in OA and $0 \%$ in OA, PCA, pseudogout (24). The authors found that the prevalence of CPP crystals in synovial fluid was $85.71 \%$ in CPP-crystalline arthritis, $19.35 \%$ in RA, $13.89 \%$ in osteoarthritis and $0 \%$ in PSA, spondyloarthritis, gout, etc. (24).

Noriko Tsuruta and collaborators (2017), demonstrate that hyperuricemia in patients with PSA is an independent risk factor for PSA with probability factors of 4.18 ( $\mathrm{P}<0.01)$ (25). Uric acid crystals are a strong stimulator of congenital immunity. Hyperuricemia can increase the crystallization of uric acid in and around the joints, thereby inducing PSA in psoriatic subjects (26).

In 2020, Felten and co-authors published a thesis demonstrating that PSA and gout are common conditions sharing a number of the same risk factors, making it challenging for them to be studied independently (27). Felten and co-authors accept that sodium urate crystals can play a pathogenic role in psoriasis and PSA. In everyday practice, the distinction between PSA associated with hyperuricemia and subaclysmic arthropathy with psoriasis is complex (27).

According to Felten and co-authors (2020), the pathogenic role of chronic hyperuricemia in the development and maintenance of PSA is based on epidemiological, clinical and fundamental arguments and therefore does not appear random. These two 
pathological processes can affect each other. This new line of thinking on gout convergence and PSA, including the role of uric crystals, may prompt a potential new approach to treatment (urate lowering therapy) among patients with active/refractory PSA $(27,28,29,30)$.

In rheumatological publications there is different information on the characteristics of synovial fluid of PSA patients (31). This has generated our interest in examining a large group of PSA patients in order to study some of the characteristics of synovial fluid of patients with psoriatic arthritis and to assess their correlation with disease activity indices through a twoyear follow-up period.

The aim of this study was to assess the presence of crystals in the synovial fluid of patients with psoriatic arthritis as biomarkers for disease activity.

Materials and methods

Over a period of 3 years (2018-2021), this study analyzed 906 synovial fluids from patients with various rheumatological diseases. Out of these, 156 patients with an established PSA diagnosis were included in this study (patients covered CASPAR criteria). Patients were followed up for at least 24 months, with follow up vists carried out every 6 months. At 0 and 6 months, 156 patients were assessed, at 12 months - 145 patients, at 18 months -123 patients and at 24 months -110 patients.

Inclusion criteria:

1. Patients with proven psoriatic arthritis (CASPAR criteria) and with synovial effusion

2. Patients who have capacity and no mental health comorbidities

3. Patients have given their consent to participate by signing informed consent form

Exclusion criteria:

1. Patients who refused to give voluntarily informed consent

2. Patients with rheumatological diseases other than PSA

3. Patients with psoriatic arthritis on biological treatment

4. Patients with decompensated cardiovascular, pulmonary or renal failure

5. Pregnant or lactating women

6. Patients who were deemed unable by the researcher to commit to the follow up schedule

7. Patients who were deemed inappropriate for inclusion at the investigator's discretion 
All work including patient data analysis, blood collection and aspiration of synovial fluid and the content of the informed consent form has been approved by the Committee for Scientific Ethics of the Medical University - Plovdiv, Protocol No 4/ 10.06.2021.

The polarization microscopy of synovial fluid was conducted by a doctoral graduate under the supervision the dissertation lead supervisor. With a dubious result, the slide with fixed synovial fluid was analyzed by a specialist histopathologist, Department of General and Pathological Anatomy, Mu - Plovdiv.

Study timeline:

The surveys included in the dissertation work were conducted between 2018 and 2021 .

Regulatory bodies in the study:

The study conduct utilised the personal participation and control of the dissertant, in cooperation with consultant rheumatologists, clinician-laboratory doctors, assistants and laboratory technicians in the Immunological Laboratory of the Institute of Immunology of Reproduction, BAS, Sofia, statistician.

Collection of primary information:

The primary information was collected during patient visits to the rheumatology clinic at The Caspela University Hospital and St. George University Hospital. Results from the patient's disease history were used, available results for monitoring the effect of treatment and for an appearance before the Committee for

\section{Polarization microscopy:}

The polarization microscope is used to determine the presence and specific optical qualities of substances that have the property of refracting double light such as crystals. Thi study used the polarization microscope Leica DM4500P (Leica Microsystems, Germany).

The studies included:

- 156 pieces of synovial fluids from PsA patients at 0 months

- 42 pieces of synovial fluids from PsA patients at 6 months, of which 9 were treated with TNF-alpha 
- 22 pieces of synovial fluids from PsA patients at 12 months, of which 7 were treated with TNF-alpha

- 28 pieces of synovial fluids from PsA patients at 18 months, of which 6 were treated with TNF-alpha

- 20 synovial fluids from PsA patients at 24 months, of which 8 were treated with TNF-alpha $\bullet 50$ serums and synovial fluid from patients with activated gonarthrosis

- 12 serums of healthy control subjects matched by sex and age

\section{Disease Activity Indexes:}

In Psoriatic Arthritis DAPSA (Disease Activity Index for Psoriatic Arthritis) was used in predominantly peripheral joint involvement in patients with PSA, which is made of the sum of 5 variables - number of swelling and painful joints, PtGA, PtP, VAS CRP. A result of $\leq$ of 14 , indicates low disease activity, a result of $\leq 28$ indicates moderate disease activity, a result of $>28$ indicates high disease activity.

The PASDAS Composite Index (Psoriatic Arthritis Disease Activity Score) combines a patient's VAS and a doctor's VAS for skin involvement, number of oedentary and painful joints, entesitic index of Lees, index for dactylitis, SF-36. A value below 1.9 is considered to indicate remission, low disease activity - 1.9-3.2, moderate disease activity 3.2-5.4, high disease activity - value above 5.4.

The mCPDAI (Composite Psoriatic Disease Activity Index) multicomponent score includes an assessment of peripheral arthritis, skin involvement, spinal involvement, entesitis, dactylitis, with a value of 0 to 3 for each domain. A value of $0-2$ is considered normal, a value of 0-3 - low disease activity, a value of 4-9 - moderate disease activity, a value over 9 - high disease activity.

Pain intensity is evaluated with a visual analog scale (VAS) - horizontal ruler $100 \mathrm{~mm}$ long, with "No pain" marked on the left side, and "Very severe pain" on the right side. After appropriate instructions, the patient notes a vertical mark on the scale according to their perception of pain at the time of examination. The result is determined by measuring the distance from point 0 to the vertical feature, and thus patients are divided into four groups: mild pain $(<40 \mathrm{~mm})$, moderate pain $(40-60 \mathrm{~mm})$, severe pain $(60-80 \mathrm{~mm})$, very severe pain (> $80 \mathrm{~mm})$.

In Health Assessment Questionaire - Disability Index (HAQ-DI), responses are noted by patients on a 4-step Likert-type scale ranging from 0 (without difficulty) to 3 (impossible to do). Higher HAQ-DI index values were associated with a higher degree of disability. Values can be interpreted in the following three categories: from 0 to 1 - mild difficulties to moderate disability; from 1 to 2 - moderate to severe disability, from 2 to 3 : severe to very severe disability. 


\section{Statistical Analysis}

Statistical analysis was performed using SPSS version 26.0 (SPSS Inc., Chicago, IL, USA). The concentrations of the parameters of iron homeostasis, inflammation and autoimmune disorders were tested for normality using the Kolmogorov-Smirnov test. Data were presented as mean \pm SD. T-test (Student's Fisher test) was used to compare two groups with normal distribution and the Mann-Whitney U test was used to compare groups with nonnormal distribution. Correlations between data were evaluated by calculating the Pearson's correlation coefficient depending on the distribution of the continuous variables. $\mathrm{P}<0.05$ was considered as statistically significant.

\section{Results}

Arthrocentesis was performed by a consultant rheumatologist on 156 patients with PSA with hydrops (145 on the knee joint, 6 on the ankle joint, 3 on the lactic joint, 2 on the shoulder joint) in compliance with antiseptic rules.

The macroscopic appearance of the synovial fluid was clear in $132(84.6 \%)$ of the patients, mildly bloodied (most likely articially in $9(5.76 \%)$ and cloudy in $15(9.61 \%)$ patients treated, with the clear synovial fluid significantly more common compared to the rest respectively $(\mathrm{t}=21.765(\mathrm{df} 155)$, sig (2-tailed) $=0.000$ and $(\mathrm{t}=18.144(\mathrm{df} 155)$, sig (2-tailed $)=$ 0.000, One-Sample Test).

In the present study, synovial fluid with good viscosity was observed in 134 (85.89\%) of the patients and altered viscosity in $22(14.10 \%)$ of the patients with the difference between the two groups being significant $(t=36.051(\mathrm{df} 155)$, sig $(2$-tailed $)=0.000$, One-Sample Test $)$.

The assessment of 156 patients with PSA and hydrops of the joint through polarization microscopy demonstrated the presence of crystals in 37 (23.71\%) of them, absence of crystals at $119(76.62 \%)$, with the difference between the two groups being significant $(\mathrm{t}=36.212$ ( $\mathrm{df}$ 155), sig $(2$-tailed $)=0.000$, One-Sample Test). Their results were compared to data from 50 patients with activated gonarthrosis. None of the patients with activated gonarthrosis demonstrated crystals in the synovial fluid with the difference between the two groups being significant $(\mathrm{p}<0.001)$.

Twenty-five (67.56\%) men had crystals in their synovial fluid and twelve $(32.43 \%)$ women had crystals in the synovial fluid, with the difference between the two groups being insignificant (Pearson Chi-Square=1,274, (df 1), Sig.(2-sided)=0.259, Fisher's Exact Test $=0.338$.

The most commonly observed crystals were from monosodium urate - in 25 (67.58\%) patients, followed by the presence of pyrophosphate crystals - in $8(21.62 \%)$ patients, lipid drops - in $2(5.4 \%)$ patients and in $2(5.4 \%)$ patients mixed crystals were found. 
Monosodium urate crystals appear as thin, sharp edged, disorderly arranged needles single or in groups (Fig. 13 and Annex 11). Calcium pyrophosphate crystals are often diamond-shaped or square-shaped, no longer than $<\mathrm{I} 0 \mu \mathrm{m}$ (Fig. 1 and Fig. 2).

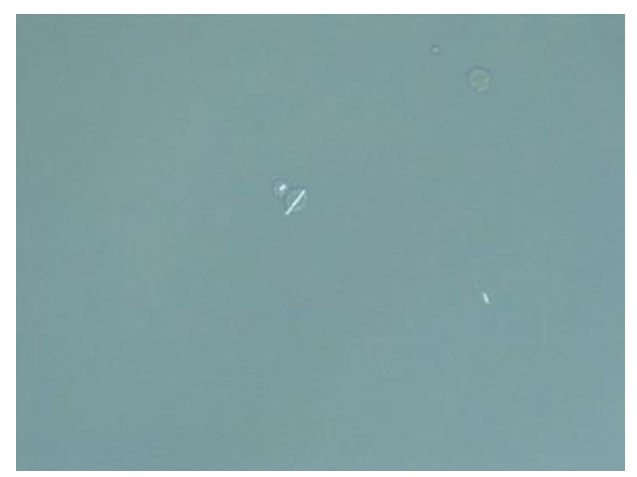

Fig. 1. Single MNU crystals phages derived from macrophages obtained by arthrocentesis of the knee joint of D.B.P.P., 56 years old, diagnosed with PsA 2014, own result.

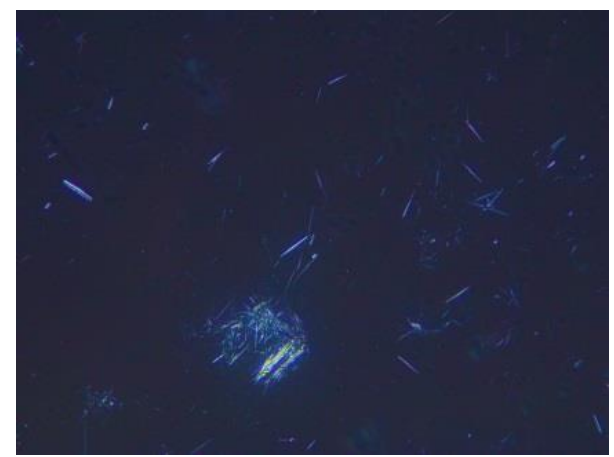

Fig. 2. Multiple MNU crystals obtained by arthrocentesis of the knee joint of Ive. 10/22 S\&P C., 59, diagnosed with PsA in 2010, own result.

After the establishment of crystal presence, patients were divided into two groups group A (37 (23.71\%) - patients with crystals in the synovial fluid and group B 119 (76.62\%) - patients without crystals. The demographic, clinical and imaging parameters of the patients suffering from PsA are presented in Tab. 1.

Tabl. 1. Demographic, clinical and imaging parameters of the 156 PsA patients included. Separation according to the availability of crystals in the synovial fluid.

\begin{tabular}{|c|c|c|c|c|c|c|c|}
\hline Parameters & $\begin{array}{l}\text { PsA } \\
n=156\end{array}$ & $\begin{array}{l}\text { Control } \\
\text { group } \\
\mathrm{n}=50\end{array}$ & $\begin{array}{l}\text { A group of } \\
\text { patients with } \\
\text { crystals } \\
n=37\end{array}$ & $\begin{array}{l}\text { A group of } \\
\text { patients } \\
\text { without } \\
\text { crystals } n=119\end{array}$ & $\mathrm{P} 1$ & $\mathrm{P} 2$ & P3 \\
\hline Age (years) & $59.0 \pm 13.18$ & $61.4 \pm 11.1$ & $62.00 \pm 9.34$ & $59.89 \pm 10.78$ & NS & NS & NS \\
\hline $\begin{array}{c}\text { Gender Women } \\
\text { Men }\end{array}$ & $\begin{array}{l}63(40.4 \%) \\
93(59.6 \%) \\
\end{array}$ & $\begin{array}{c}20(40 \%) \\
30(60 \%) \\
\end{array}$ & $\begin{array}{l}12(32.43 \%) \\
25(67.56 \%)\end{array}$ & $\begin{array}{l}51(42.85 \%) \\
68(57.15 \%\end{array}$ & NS & NS & $\begin{array}{l}0.024 * \\
0.031 *\end{array}$ \\
\hline BMI & $29,93 \pm 3,88$ & $27,48 \pm 4,5$ & $28,14 \pm 3,38$ & $30.11, \pm 2,14$ & NS & $\mathrm{NS}$ & NS \\
\hline $\begin{array}{l}\text { Diagnosis } \\
\text { duration }\end{array}$ & $11.96 \pm 8.17$ & - & $11.23 \pm 7.9$ & $10.55 \pm 3-09$ & NS & NS & NS \\
\hline
\end{tabular}




\begin{tabular}{|c|c|c|c|c|c|c|c|}
\hline $\begin{array}{l}\text { Involvement } \\
\text { Polyarticular } \\
\text { Oligoarticular } \\
\text { Axillary } \\
\end{array}$ & $\begin{array}{l}24.4 \% \\
53.2 \% \\
22.4 \%\end{array}$ & - & $\begin{array}{l}38.9 \% \\
52.9 \% \\
8.2 \%\end{array}$ & $\begin{array}{l}36.1 \% \\
43.8 \% \\
20.1 \%\end{array}$ & - & - & $\begin{array}{l}\text { NS } \\
\text { NS } \\
0.035^{*}\end{array}$ \\
\hline $\begin{array}{l}\text { Presence of skin } \\
\text { psoriasis }\end{array}$ & $138(88.4 \%)$ & - & $35(94.59 \%)$ & $103(86.55 \%)$ & - & - & $0.028 *$ \\
\hline Nail involvement & $99(63.5 \%)$ & - & $33(89.18 \%)$ & $66(66.66 \%)$ & - & - & $0.037 *$ \\
\hline $\begin{array}{ll}\begin{array}{l}\text { Presence } \\
\text { dactylitis }\end{array} & \text { of } \\
\end{array}$ & $48(30.8)$ & - & $35(94.59 \%)$ & $13(10.92 \%)$ & - & - & $0.001 *$ \\
\hline $\begin{array}{ll}\begin{array}{l}\text { Presence } \\
\text { enthesitis }\end{array} & \text { on } \\
\end{array}$ & $123(78.8 \%)$ & - & $31(83.78 \%)$ & $92(77.31 \%)$ & - & - & $0.025^{*}$ \\
\hline $\begin{array}{ll}\begin{array}{l}\text { Presence } \\
\text { enthesitis }\end{array} & \text { on } \\
\end{array}$ & $121(77.6 \%)$ & - & $27(72.97 \%)$ & $84(78.99 \%)$ & - & - & $0.043^{*}$ \\
\hline $\begin{array}{l}\text { Accompanying } \\
\text { diseases } \\
\text { Hypertension } \\
\text { Diabetes } \\
\text { Ischemic heart disease } \\
\text { Hyperureaemia } \\
\text { Dyslipidemia } \\
\text { Obesity }\end{array}$ & $\begin{array}{l}114(73.1 \%) \\
125(80.1 \% \\
61(39.1 \%) \\
114,73.1 \% \\
99,63.5 \%) \\
132,84.6 \%\end{array}$ & $\begin{array}{l}41(82 \%) \\
13(26 \%) \\
9(18 \%) \\
13(26 \%) \\
13(26 \%) \\
25(50 \%)\end{array}$ & $\begin{array}{l}30(81.08 \%) \\
30(81.08 \%) \\
26(70.27 \%) \\
33(89.18 \%) \\
30(81.08 \%) \\
34(91.89 \%)\end{array}$ & $\begin{array}{l}82(70.58 \%) \\
96(79.83 \%) \\
35(29.41) \\
81(68.06 \%) \\
69(57.98 \%) \\
98(82.35 \%)\end{array}$ & $\begin{array}{l}\text { NS } \\
0.01 * \\
0.001 * \\
0.001 * \\
0.001 * \\
0.001 *\end{array}$ & $\begin{array}{l}0.038^{*} \\
0.001 * \\
0.001 * \\
0.001 * \\
0.001 * \\
0.001 *\end{array}$ & $\begin{array}{l}0.039^{*} \\
0.02^{*} \\
0.001^{*} \\
0.02^{*} \\
0.03^{*} \\
0.034^{*}\end{array}$ \\
\hline Smoking & $66(42.3 \%)$ & $19(38 \%)$ & $26(70.27 \%)$ & $40(33.81 \%)$ & $0.001^{*}$ & NS & $0.001 *$ \\
\hline CУE mm/час & $42,01 \pm 20.8$ & $13,51 \pm 3.8$ & $56,02 \pm 18.34$ & $39,56 \pm 7.28$ & $0.001 *$ & $0.001 *$ & $0.001 *$ \\
\hline $\begin{array}{l}\text { C-peactiv protein } \\
\mathrm{g} / \mathrm{l}\end{array}$ & $43.72 \pm 23.6$ & $9.44 \pm 2.11$ & $54,35 \pm 12.76$ & $31,34 \pm 4.66$ & $0.001 *$ & $0.001 *$ & $0.001 *$ \\
\hline
\end{tabular}

P1 - the difference between the results of patients with crystals compared to the control group of subjects

P2 - the significant difference between the results of patients without crystals compared to the control group of subjects

P1 - the significant difference between the results of patients with crystals compared to the results of patients without crystals

Most often, patients without crystals in the synovial fluid indicated that they experienced mild to moderate pain $(75.6 \%)$, while $90.5 \%$ of patients with crystals in the synovial fluid indicated that they had severe to intolerable severe pain, as indicated by VAS (table 2).

Table 2. Assessment of pain severity according to visual analogue scale (VAS) in mm in 156 PSA patients, according to the presence of crystals in their synovial fluid.

Table 2. Assessment of pain severity according to visual analogue scale (VAS) in mm in 156 PsA patients, according to the presence of crystals in their synovial fluid.

\begin{tabular}{|l|l|l|l|}
\hline \multirow{2}{*}{ Patient pain assessment (VAS) in\% } & $\begin{array}{l}\text { Presence of crystals } \\
\text { in synovial fluid }\end{array}$ & \\
\cline { 2 - 3 } & & $\begin{array}{l}\text { Not } \\
\text { present }\end{array}$ & Total \\
\hline
\end{tabular}




\begin{tabular}{||l|l|l|l|l|}
\hline \multirow{3}{*}{ Mild to moderate pain } & Number & 90 & 2 & 92 \\
\cline { 2 - 5 } & $\%$ VAS O visit & $97,8 \%$ & $2,2 \%$ & $100,0 \%$ \\
\cline { 2 - 5 } & $\%$ of patients with crystals & $75,6 \%$ & $5,4 \%$ & $59,0 \%$ \\
\hline \multirow{5}{*}{ Moderate pain } & Number & 21 & 1 & 22 \\
\cline { 2 - 5 } & $\%$ VAS O visit & $95,5 \%$ & $4,5 \%$ & $100,0 \%$ \\
\cline { 2 - 5 } & $\%$ of patients with crystals & $17,6 \%$ & $2,7 \%$ & $14,1 \%$ \\
\hline \multirow{5}{*}{ Unbere pain } & Number & 6 & 15 & 21 \\
\cline { 2 - 5 } & $\%$ VAS O visit & $28,6 \%$ & $71,4 \%$ & $100,0 \%$ \\
\cline { 2 - 5 } & $\%$ of patients with crystals & $5,0 \%$ & $40,5 \%$ & $13,5 \%$ \\
\hline & Number & 2 & 19 & 21 \\
\cline { 2 - 5 } & $\%$ VAS O visit & $9,5 \%$ & $90,5 \%$ & $100,0 \%$ \\
\cline { 2 - 5 } & $\%$ of patients with crystals & $1,7 \%$ & $51,4 \%$ & $13,5 \%$ \\
\hline
\end{tabular}

Pearson Chi-Square test was conducted and indicated a coefficient of 106.221, (df 3), sig. (2-sided $)=0.000$. Kendall's tau-b and Spearman Correlation are also with sig. (2sided $=0.000$, therefore it was assumed that patients with crystals in the synovial fluid experience more pain as tested by VAS in millimeters, compared to patients without crystals.

Most often, synovial fluid crystal-free patients had low disease activity (54.6\%) while $75.7 \%$ of patients with crystals in the synovial fluid had high disease activity as assessed by the DAPSA scale (table 3).

Tabl. 3. Assessment of disease activity by DAPSA-scale of 156 patients with PsA, according to the presence of crystals in their synovial fluid.

\begin{tabular}{|c|c|c|c|c|}
\hline \multirow{2}{*}{\multicolumn{2}{|c|}{ Disease activity state as assessed by DAPSA }} & \multicolumn{2}{|c|}{$\begin{array}{l}\text { Presence of crystals in } \\
\text { synovial fluid }\end{array}$} & \multirow[b]{2}{*}{ Total } \\
\hline & & \multirow{2}{*}{$\begin{array}{l}\text { Present } \\
65\end{array}$} & \multirow{2}{*}{\begin{tabular}{|l} 
Not \\
present \\
6 \\
\end{tabular}} & \\
\hline \multirow[t]{3}{*}{ Low disease activity } & Number & & & 71 \\
\hline & $\%$ DAPSA 0 visit & $91.5 \%$ & $8.5 \%$ & $100,0 \%$ \\
\hline & $\%$ of patients with crystals & $54.6 \%$ & $16.2 \%$ & $45.5 \%$ \\
\hline \multirow[t]{3}{*}{ Moderate disease activity } & Number & 35 & 3 & 38 \\
\hline & $\%$ DAPSA 0 visit & $92.1 \%$ & $7.9 \%$ & $100.0 \%$ \\
\hline & $\%$ of patients with crystals & $29.4 \%$ & $8.1 \%$ & $24.4 \%$ \\
\hline \multirow[t]{3}{*}{ High disease activity } & Number & 19 & 28 & 47 \\
\hline & $\%$ DAPSA 0 visit & $40.4 \%$ & $59.6 \%$ & $100.0 \%$ \\
\hline & $\%$ of patients with crystals & $16.0 \%$ & $75.7 \%$ & $30.1 \%$ \\
\hline
\end{tabular}

The Pearson Chi-Square test was conducted at a factor of 47.805, (df 2), sig. (2sided $=0.000$. Kendall's tau-b and Spearman Correlation also had sig. (2-sided) $=0.000$, therefore it was assumed that patients with crystals in the synovial fluid have a significantly higher disease activity as indicated by DAPSA-scale compared to patients without crystals. 
Most often, patients without crystals in the synovial fluid had low disease activity (86.5\%), while $35.1 \%$ of patients with crystals in the synovial fluid had high disease activity, as indicated by the PASDAI Composite Index (Table 4).

Tabl. 4. Assessment of disease activity by the PASDAI composite index of 156 patients with PsA, according to the presence of crystals in their synovial fluid.

\begin{tabular}{|c|c|c|c|c|}
\hline \multirow{2}{*}{\multicolumn{2}{|c|}{ Disease activity state as assessed by PASDAI }} & \multicolumn{2}{|c|}{$\begin{array}{l}\text { Presence of crystals in } \\
\text { synovial fluid }\end{array}$} & \multirow[b]{2}{*}{ Total } \\
\hline & & \multirow{2}{*}{\begin{tabular}{|l} 
Present \\
77
\end{tabular}} & \multirow{2}{*}{\begin{tabular}{|l} 
Not \\
Present
\end{tabular}} & \\
\hline \multirow[t]{3}{*}{ Low disease activity } & Number & & & 89 \\
\hline & $\%$ PASDAI 0 visit & $86.5 \%$ & $13.5 \%$ & $100.0 \%$ \\
\hline & $\%$ of patients with crystals & $64.7 \%$ & $32.4 \%$ & $57.1 \%$ \\
\hline \multirow[t]{3}{*}{ Moderate disease activity } & Number & $49.4 \%$ & $7.7 \%$ & $57.1 \%$ \\
\hline & $\%$ within PASDAI 0 visit & 39 & 12 & 51 \\
\hline & $\%$ of patients with crystals & $76.5 \%$ & $23.5 \%$ & $100.0 \%$ \\
\hline \multirow[t]{3}{*}{ High disease activity } & Number & 3 & 13 & 16 \\
\hline & $\%$ within PASDAI 0 visit & $18.8 \%$ & $81.3 \%$ & $100.0 \%$ \\
\hline & $\%$ of patients with crystals & $2.5 \%$ & $35.1 \%$ & $10.3 \%$ \\
\hline
\end{tabular}

The Pearson Chi-Square test was conducted at odds of 34.425 , (df 2), sig. (2sided $=0.000$. Kendall's tau-b and Spearman Correlation also had sig. (2-sided) $=0.000$, therefore it was assumed that patients with crystals in the synovial fluid have a significantly higher disease activity studied by the PASDAI composite index compared to patients without crystals.

Most often, patients without crystals in the synovial fluid indicated that they had low disease activity $(75.8 \%$ ), while $67.6 \%$ of patients with crystals in the synovial fluid indicated that they had high disease activity as assessed by the composite index mCPDAI (Tab.: 5).

Tabl. 5. Assessment of disease activity by the composite index mCPDAI of 156 patients with PsA, according to the presence of crystals in their synovial fluid.

\begin{tabular}{|l|l|l|l|l|}
\hline \multirow{2}{*}{ Disease activity state as assessed by mCPDAI } & \multicolumn{2}{|l|}{$\begin{array}{l}\text { Presence of crystals in } \\
\text { synovial fluid }\end{array}$} & \\
\cline { 2 - 4 } & & & \multirow{2}{*}{$\begin{array}{l}\text { Not } \\
\text { present }\end{array}$} & Total \\
\hline \multirow{3}{*}{ Low disease activity } & Number & 90 & 8 & 98 \\
\cline { 2 - 5 } & $\%$ mCPDAI 0 visit & $91.8 \%$ & $8.2 \%$ & $100.0 \%$ \\
\cline { 2 - 5 } & $\%$ of patients with crystals & $75.6 \%$ & $21.6 \%$ & $62.8 \%$ \\
\hline \multirow{3}{*}{ Moderate disease activity } & Number & 14 & 4 & 18 \\
\cline { 2 - 5 } & $\%$ mCPDAI 0 visit & $77.8 \%$ & $22.2 \%$ & $100.0 \%$ \\
\cline { 2 - 5 } & $\%$ of patients with crystals & $11.8 \%$ & $10.8 \%$ & $11.5 \%$ \\
\hline
\end{tabular}




\begin{tabular}{||l|l|l|l|l|}
\hline \multirow{3}{*}{ High disease activity } & Number & 15 & 25 & 40 \\
\cline { 2 - 5 } & $\%$ mCPDAI 0 visit & $37.5 \%$ & $62.5 \%$ & $100.0 \%$ \\
\cline { 2 - 5 } & $\%$ of patients with crystals & $12.6 \%$ & $67.6 \%$ & $25.6 \%$ \\
\hline
\end{tabular}

The Pearson Chi-Square test was conducted at odds of 46.380, (df 2), sig. Kendall's tau-b and Spearman Correlation also had sig. (2-sided) $=0.000$, so it was assumed that patients with crystals in the synovial fluid have a significantly higher disease activity as assessed by the mCPDAI composite index compared to patients without crystals.

Most often, patients without crystals in the synovial fluid indicated that they had mild difficulties in performing physical exertion $(57.1 \%)$, while $21.2 \%$ of patients with crystals in the synovial fluid indicated that they had high disease activity as assessed by the HAQ-DI physical capacity index (table: 6).

Table: 6. HaQ-DI physical capacity assessment of 156 patients with PsA according to the presence of crystals in their synovial fluid.

\begin{tabular}{|c|c|c|c|c|}
\hline & & $\begin{array}{l}\text { Presenc } \\
\text { synovia }\end{array}$ & $\begin{array}{l}\text { crystals in } \\
\text { iid }\end{array}$ & \\
\hline Disease activity state as assess & ed by HAQ-DI & Present & $\begin{array}{l}\text { Not } \\
\text { present }\end{array}$ & Total \\
\hline Mild to moderate difficulty & Number & 68 & 10 & 78 \\
\hline & $\%$ HAQ-DI 0 visit & $87.2 \%$ & $12.8 \%$ & $100.0 \%$ \\
\hline & $\%$ of patients with crystals & $57.1 \%$ & $27.0 \%$ & $50.0 \%$ \\
\hline to severe & Number & 40 & 5 & 45 \\
\hline disability & $\%$ HAQ-DI 0 visit & $88.9 \%$ & $11.1 \%$ & $100.0 \%$ \\
\hline & $\%$ of patients with crystals & $33.6 \%$ & $13.5 \%$ & $28.8 \%$ \\
\hline Severe to very severe & Number & 11 & 22 & 33 \\
\hline disability & $\%$ HAQ-DI 0 visit & $33.3 \%$ & $66.7 \%$ & $100.0 \%$ \\
\hline & $\%$ of patients with crystals & $9.2 \%$ & $59.5 \%$ & $21.2 \%$ \\
\hline
\end{tabular}

The Pearson Chi-Square test was conducted at a factor of 42.717, (df 2), sig. (2sided $=0.000$. Kendall's tau-b and Spearman Correlation also had sig. (2-sided) $=0.000$, therefore it was assumed that patients with crystals in the synovial fluid have a significantly lower physical capacity as assessed by HAQ-DIs compared to patients without crystals.

The non-parametric tests Kendall's Tau_b and Spearman's Rho indicated sigfinicant strong correlations between VAS, DAPSA, PASDAI, mCPDAI and HAQ-DI and the presence of crystals in the synovial fluid of patients with PsA $(\mathrm{p}<0.01)$ during baseline (prior to treatment with TNF-a-blockers). The same analysis found significant moderate correlations DAPSA and the presence of crystals in the synovial fluid of patients, VAS and mCPDAI, as well as between PASDAI and the presence of crystals in the synovial fluid of patients with PSA and VAS, mCPDAI in the same patient group had significant correlations with DAPSA, 
HAQ-DI, VAS and the presence of crystals in the synovial fluid of PSA patients. HAQ-DI in the same patient group had significant correlations with mCPDAI, VAS and the presence of crystals in the synovial fluid of patients with PsA.

The presence of monosodium urate crystals significantly correlates with all scales and indices for disease activity - VAS for pain, DAPSA, PASDAI, mCPDAI and HAQ-DI, according to the conducted analyses of Kendall's tau_b and Spearman's rho $(p<0.01)$ at baseline (prior to treatment with TNF-a-blockers).

We followed up all patients with crystals present at baseline (visit 0). Out of these, 25 $(67.56 \%)$ started treatment with an anti-TNF blocker and 12 (32.44\%) remained on conventional therapy, with the difference between the two groups being significant $(\mathrm{U}=2.18$, $\mathrm{p}<0.05$ ). In the following months this trend persisted, without significant difference between the groups due to the small number of patients. In some patients (up to 5 patients per visit at 18 months), the study of synovial fluid confirmed the establishment of crystals at visit 0 (Table 7).

Table 7. Monitoring of the number of patients according to the method of treatment (conventional/biological DMARD) and the presence or absence of crystals in the synovial fluid of patients with PsA.

\begin{tabular}{|c|c|c|c|c|}
\hline Indicators & № & $\begin{array}{l}\text { Numbe } \\
\mathrm{r} \quad \text { of } \\
\text { patient } \\
\mathrm{s} \\
\end{array}$ & Presence of crystals & $\begin{array}{l}\text { Absence } \\
\text { of } \\
\text { crystals } \\
\end{array}$ \\
\hline $\begin{array}{l}\text { Crystals in synovial fluid at } 0 \\
\text { months }\end{array}$ & 1 & 156 & 37 & 119 \\
\hline $\begin{array}{l}\text { Crystals in synovial fluid at } 6 \\
\text { months - cDMARDs }\end{array}$ & 2 & 33 & 14 (7 patients with crystals at visit 0 ) & 19 \\
\hline $\begin{array}{l}\text { Crystals in synovial fluid at } 6 \\
\text { months - bDMARD }\end{array}$ & 3 & 9 & 3 (3 patients with crystals at visit 0 ) & 6 \\
\hline $\begin{array}{l}\text { Crystals in synovial fluid at } 12 \\
\text { months - cDMARDs }\end{array}$ & 4 & 15 & 6 (4 patients with crystals at visit 0 ) & 9 \\
\hline $\begin{array}{l}\text { Crystals in synovial fluid at } 12 \\
\text { months - bDMARDs }\end{array}$ & 5 & 7 & 3 (2 patients with crystals at visit 0 ) & 4 \\
\hline $\begin{array}{l}\text { Crystals in synovial fluid at } 18 \\
\text { months - cDMARDs }\end{array}$ & 6 & 22 & 8 (5 patients with crystals at visit 0 ) & 14 \\
\hline $\begin{array}{l}\text { Crystals in synovial fluid at } 18 \\
\text { months - bDMARDs }\end{array}$ & 7 & 6 & $2(2$ patients with crystals at visit 0$)$ & 4 \\
\hline $\begin{array}{l}\text { Crystals in synovial fluid at } 24 \\
\text { months - cDMARDs }\end{array}$ & 8 & 12 & 6 (3 patients with crystals at visit 0 ) & 6 \\
\hline $\begin{array}{l}\text { Crystals in synovial fluid at } 24 \\
\text { months - bDMARDs }\end{array}$ & 9 & 8 & 3 (2 patients with crystals at visit 0 ) & 5 \\
\hline
\end{tabular}




\section{Discussion}

The presence of crystals in the synovial fluid is relevant in crystal-induced arthritis, since their presence leads to acute inflammation $(13,32)$. Polarization microscopic procedure for crystal assessment is not always easy since their concentration in the synovial fluid may be small, making their identification difficult.

Undoubtedly, it is important for rheumatologies to establish the presence of crystals, and the greater the crystal load in the synovial fluid, the more likely observers are to identify, assess and correctly diagnose them. The examination of synovial fluid is a minimally invasive procedure - it requires patient consent and an experienced consultant rheumatologist to aspirat enough synovial fluid under ultrasound control for examination.

According to the results of this study, the macroscopic appearance of synovial fluid in the studied group of patients suffering from PSA is most often clear and with good viscosity, or cloudy (in $9.61 \%$ ) or with altered viscosity $(14.10 \%)$. This is also consistent with previous studies establishing that the synovial fluid is cloudy in the presence of a microbiological causative agent or a large amount of leukocytes (33).

The study of 156 patients with PsA and joint hydrops through polarization microscopy demonstrated the presence of crystals in 37 (23.71\%) of them, absence of crystals in 119 (76.62\%) of them, with the difference between the two groups being significant $(\mathrm{t}=36.212$ ( $\mathrm{df}$ $155)$, sig $=0.000$. These results contradict the results of some authors such as Oliviero and coauthors, who found MSU crystals in the synovial fluid in 3.34\% (23) of PSA patients and Galozzi and co-authors, who found MSU crystals in the synovial fluid in 9.53\% (24) of PSA patients.

Our results seem more likely, as both Noriko Tsuruta and associates (2017) demonstrate that hyperuricemia in patients with PSA is an independent risk factor for PSA with probability factors of 4.18 ( $\mathrm{p}<0.01$ ) (25). According to Tsuruta and co-authors, hyperuricemia can increase the crystallization of uric acid in and around the joints, thereby inducing PsA in psoriatic subjects (25).

The most commonly observed crystals in the synovial fluid of PsA patients are from monosodium urate $(67.58 \%)$, followed by the presence of pyrophosphate crystals $(21.62 \%)$, lipid drops $(5.4 \%)$, and in $2(5.4 \%)$ patients mixed crystals were found. These findings contradict the findings of Oliviero and co-authors, which found that calcium pyrophosphate crystals are more common in PSA patients compared to MNU crystals (23). Unlike our results, in which we identified two patients with the presence of two types of crystals, most authors agree that there is only one type of crystal in the synovial fluid of a PsA patient (23, 25).

The presence of crystals in uric acid correlates with all scales and indices for disease activity - VAS for pain, DAPSA, PASDAI, mCPDAI and HAQ-DI during baseline (prior to treatment with TMF-a-blockers) in our patients, as indicated by Kendall's Tau_b and 
Spearman's Rho $(\mathrm{p}<0.01)$ tests. We did not find such results in theexisting e literature, which is why we cannot compare them to ours.

\section{Conclusions}

1. The macroscopic appearance of synovial fluid from patients with psoriatic arthritis was clear in $84.6 \%$ of the observed patients, slightly bloodied at $5.76 \%$ and cloudy at $9.61 \%$. It has a good viscosity in $85.89 \%$ of patients.

2. Crystals in synovial fluid were present in $23.71 \%$ of patients with psoriatic arthritis, and they are established more often in men. Most commonly, crystals were monosodium urate $(67.58 \%)$ crystals, calcium pyrophosphate $(21.62 \%)$ crystals, lipid drops $(5.4 \%)$, and mixed crystals were found in $5.4 \%$ of patients.

3. $\quad 75.7 \%$ of patients with crystals in the synovial fluid had high disease activity as assessed by the DAPSA scale. $35.1 \%$ of patients with crystals in the synovial fluid had high disease activity, as assessed by the PASDAI composite index. $67.6 \%$ of patients with crystals in the synovial fluid had high disease activity as assessed by the mCPDAI composite index.

4. The presence of monosodium urate crystals significantly correlates with all scales and indices for disease activity - VAS for pain, DAPSA, PASDAI, mCPDAI and HAQ-DI. $67.56 \%$ of patients with established crystals started treatment with an anti-TNF blocker at the discretion of the treating rheumatologist due to disease activity.

\section{Conclusion}

Examining the synovial fluid in PsA patients is a necessary minimally invasive procedure in cases of joint effusion, since the presence of synovial fluid crystals is a significant indicator of disease severity. The current analyses demonstrates that the presence of synovial fluid crystals in PsA patients can be used as a biomarker for disease severity and the necessity to commence biological treatment (most often TNF-a-blocker).

\section{References}

1. Alamanos Y., P. Voulgari, A. Drosos, ,Incidence and prevalence of psoriatic arthritis: a systematic review“, Rheumatol., 2008 Jul;35 (7), p 1354-8. (Article, PubMed, Google Scholar)

2. Augustin M.,J. Vietri,H. Tian,I. Gilloteau, „Incremental burden of cardiovascular comorbidity and psoriatic arthritis among adults with moderate-to-severe psoriasis in five European countries“, J. Eur. Acad. Dermatol. Venereol. 2017, 31, p 1316-1323.

https://doi.org/10.1111/jdv.14286, Article, PubMed, Google Scholar)

3. Belasco J., N. Wei, "Psoriatic arthritis: what is happening at the joint?", Rheumatol Ther 2019; 6: p 305-15. PMID: 31102105 PMCID: PMC6702660 DOI: 10.1007/s40744-0190159-1 (Article, PubMed, Google Scholar) 
4. Ritchlin CT, Colbert RA, Gladman DD (2017) Psoriatic arthritis. N Engl J Med 376(10):957-970. https://doi.org/10.1056/NEJMra1505557, Article, PubMed, Google Scholar

5. Penkava F, Velasco-Herrera MDC, Young MD, Yager N, Nwosu LN, Pratt AG, Lara AL, Guzzo C, Maroof A, Mamanova L, Cole S, Efremova M, Simone D, Filer A, Brown CC, Croxford AL, Isaacs JD, Teichmann S, Bowness P, Behjati S, Hussein Al-Mossawi M., „Single-cell sequencing reveals clonal expansions of pro-inflammatory synovial CD8 T cells expressing tissue-homing receptors in psoriatic arthritis“, Nat Commun. 2020 Sep 21;11(1):4767.

doi: 10.1038/s41467-020-18513-6. (Article, PubMed, Google Scholar)

6. Altobelli E, Angeletti PM, Piccolo D, De Angelis R., „Synovial Fluid and Serum Concentrations of Inflammatory Markers in Rheumatoid Arthritis, Psoriatic Arthritis and Osteoarthitis: A Systematic Review“, Curr Rheumatol Rev. 2017;13(3):170-179.

doi: $10.2174 / 1573397113666170427125918$.

7. Tang MW, Garcia S, Malvar Fernandez B, Gerlag DM, Tak PP, Reedquist KA., „Rheumatoid arthritis and psoriatic arthritis synovial fluids stimulate prolactin production by macrophages“, J Leukoc Biol. 2017 Sep;102(3):897-904.

doi: 10.1189/jlb.2A0317-115RR, (Article, PubMed, Google Scholar)

8. Shelley W. Judkins, P. Joanne Cornbleet, „Synovial Fluid Crystal Analysis“, Laboratory Medicine, Volume 28, Issue 12, 1 December 1997, Pages 774-779, https://doi.org/10.1093/labmed/28.12.774, (Article, PubMed, Google Scholar)

9. DANIEL J. MCCARTY, M.D., JOSEPH L. HOLLANDER, M.D., F.A.C.P., „IDENTIFICATION OF URATE CRYSTALS IN GOUTY SYNOVIAL FLUID“, Article 1 March 1961, https://doi.org/10.7326/0003-4819-54-3-452, (Article, PubMed, Google Scholar)

10. Krey PR, Kowalec JG., „Common forms of arthritis. Clinical consultations“, Obstet Gynaecol1995;7:1:57-66.Google Scholar

11. Pal, B., Nash, J., Oppenheim, B. et al.,Is routine synovial fluid analysis necessary? Lessons and recommendations from an audit. Rheumatology International 18, 181-182 (1999). https://doi.org/10.1007/s002960050082(Article, PubMed, Google Scholar)

12. Min Jeong Ji, Hee Jung Ryu, Jeong Hee Hong, „Synovial Fluid of Patient With Rheumatoid Arthritis Enhanced Osmotic Sensitivity Through the Cytotoxic Edema Module in Synoviocytes, Front Cell Dev Biol, 2021 Aug 31;9:700879.

https://doi.org/10.3389/fcell.2021.700879, doi: 10.3389/fcell.2021.700879 (Article, PubMed, Google Scholar)

13. Berendsen D, T Neogi, W J Taylor, N Dalbeth, T L Jansen, “Crystal identification of synovial fluid aspiration by polarized light microscopy. An online test suggesting that our 
traditional rheumatologic competence needs renewed attention and training“, 2017, Clin Rheumatol Mar;36(3):641-647. doi: 10.1007/s10067-016-3461-0, PMID: 27837341

DOI: 10.1007/s10067-016-3461-0, https://doi.org/10.1007/s10067-016-3461-0

14. Swan A., H Amer, and P Dieppe, ,The value of synovial fluid assays in the diagnosis of joint disease: a literature survey“, 2002, Ann Rheum Dis. 2002 Jun; 61(6): 493-498. doi: 10.1136/ard.61.6.493, PMCID: PMC1754135, PMID: 12006320

15. Ropes M., W. Bauer, „Synovial fluid changes in joint disease“, Cambridge Massachusetts: Harvard University Press, 1953.

16. Shmerling R H, „Synovial fluid analysis. A critical reappraisal“, 1994, Rheum Dis Clin North Am, 1994 May;20(2):503-12

17. Rolle NA, Jan I, Sibbitt WL Jr, Band PA, Haseler LJ, Hayward WA, Muruganandam M, Emil NS, Fangtham M, Bankhurst AD., „Extractable synovial fluid in inflammatory and non-inflammatory arthritis of the knee, ,Clin Rheumatol. 2019 Aug;38(8):2255-2263.

doi: 10.1007/s10067-019-04524-2.

18. Zell M, Zhang D, FitzGerald J., „Diagnostic advances in synovial fluid analysis and radiographic identification for crystalline arthritis, „Curr Opin Rheumatol. 2019 Mar;31(2):134-143.

doi: 10.1097/BOR.0000000000000582.

19. Meyer MM, Marks LA, Aslam F., „Clinical implications of synovial fluid specimen handling for crystal associated arthritides: A systematic review“,Int J Rheum Dis. 2021 Jan;24(1):10-20. doi: 10.1111/1756-185X.14019. PMID: 33150706

20.Raychaudhuri SP, Wilken R, Sukhov AC, Raychaudhuri SK, Maverakis E (2017) Management of psoriatic arthritis: early diagnosis, monitoring of disease severity and cutting edge therapies. J Autoimmun 76:21-37. https://doi.org/10.1016/j.jaut.2016.10.009

21. Boumans D., M. Hettema, H Vonkeman et al.,, „The added value of synovial fluid centrifugation for monosodium urate and calcium pyrophosphate crystal detection", Clin Rheumatol., 2017 Jul;36 (7):1599-1605. doi: 10.1007/s10067-017-3633-6.

22. Venkatasubramaniam K V, G B Bluhm, J M Riddle, „Psoriatic arthropathy and crystal-induced synovitis“, 1980, J Rheumatol, Mar-Apr 1980;7(2):213-7. PMID: 7373624

23. Oliviero Fr., Ann. Scanu, P. Galozzi et al., "Prevalence of calcium pyrophosphate and monosodium urate crystals in synovial fluid of patients with previously diagnosed joint diseases“, Joint Bone Spine, 2013 May; 80(3), p 287-90,

https://doi.org/10.1016/j.jbspin.2012.08.006 
24. Galozzi P., Fr. Oliviero, P. Frallonardo, „The prevalence of monosodium urate and calcium pyrophosphate crystals in synovial fluid from wrist and finger joints“, Rheumatol. Int., 2016 Mar; 36(3), p 443-6, doi: 10.1007/s00296-015-3376-0.

25. Tsuruta N.,Shi Imafuku,Y Narisawaq "Hyperuricemia is an independent risk factor for psoriatic arthritis in psoriatic patients”, J Dermatol, 2017 Dec;44(12):1349-1352. doi: 10.1111/1346-8138.13968., https://doi.org/10.1111/1346-8138.13968

26. Tripolino C, Ciaffi J, Ruscitti P, Giacomelli R, Meliconi R, Ursini F., "Hyperuricemia in Psoriatic Arthritis: Epidemiology, Pathophysiology, and Clinical Implications", Front Med (Lausanne). 2021 Sep 22;8:737573. doi: 10.3389/fmed.2021.737573.

27. Felten, R., Duret, PM., Gottenberg, JE. et al. At the crossroads of gout and psoriatic arthritis: "psout". Clin Rheumatol 39, 1405-1413 (2020). https://doi.org/10.1007/s10067-02004981-0

28. Arevalo AB, Haddadin F, Contreras G et al (2019) Sat0371 Cardiovascular Impact of Hyperuricemia in Patients with Psoriatic Arthritis. Ann Rheum Dis 78:1268-1268. https://doi.org/10.1136/annrheumdis-2019-eular.1674

29. Raychaudhuri SP, Wilken R, Sukhov AC, Raychaudhuri SK, Maverakis E (2017) Management of psoriatic arthritis: early diagnosis, monitoring of disease severity and cutting edge therapies. J Autoimmun 76:21-37. https://doi.org/10.1016/j.jaut.2016.10.009

30. O'Connor PJ (2013) Crystal deposition disease and psoriatic arthritis. Semin Musculoskelet Radiol 17:74-79. https://doi.org/10.1055/s-0033-1333940

31. Gottlieb Al., Joseph F. Merola, „Psoriatic arthritis for dermatologists“, Journal of Dermatological Treatment, 2019, 31:7, 662-679, DOI: 10.1080/09546634.2019. 1605142.

32. Boumans D., M. Hettema, H Vonkeman et al.,, „The added value of synovial fluid centrifugation for monosodium urate and calcium pyrophosphate crystal detection“, Clin Rheumatol., 2017 Jul;36 (7):1599-1605. doi: 10.1007/s10067-017-3633-6.

33. Hollander JL, Reginato A, Torralba TP,„Examination of synovial fluid as a diagnostic aid in arthritis, Book “Classic Papers in Rheumatology”,Edition1st Edition,,First Published,2001,ImprintCRC Press,,Pages2,eBook ISBN,9780429218316 